\title{
Application of closed kinematic chain exercises with eccentric and strength exercises for the shoulder injuries prevention in student rock climbers: a randomized controlled trial
}

\author{
SERHII KOZIN ${ }^{1,2,3}$, MARIAN CRETU ${ }^{4}$, ZHANNETA KOZINA $^{1,2}$, ANDRII CHERNOZUB $^{5}$, \\ OLENA RYEPKO $^{1,2}$, TETIANA SHEPELENKO ${ }^{6}$, IRYNA SOBKO ${ }^{1,2}$, MARIIA OLEKSIUK $^{7}$ \\ ${ }^{1}$ Department of Olympic and Professional Sport, Sport Games and Tourism, \\ H.S. Skovoroda Kharkiv National Pedagogical University, Kharkiv, Ukraine. \\ ${ }^{2}$ Kinesiology Laboratory, H.S. Skovoroda Kharkiv National Pedagogical University, Kharkiv, Ukraine. \\ ${ }^{3}$ Department of Physical Rehabilitation and Health, National University of Pharmacy, Kharkiv, Ukraine. \\ ${ }^{4}$ Faculty of Science, Physical Education and Informatics, University of Pitesti, Romania. \\ ${ }^{5}$ Department of Olympic and Professional Sports, Petro Mohyla Black Sea National University, Mykolaiv, Ukraine. \\ ${ }^{6}$ Department of Physical Education and Sports, Ukrainian State University of Railway Transport, Kharkiv, Ukraine. \\ ${ }^{7}$ Department of Theory and Methods of Labor Training and Technology, \\ Taras Shevchenko Kremenets Regional Humanitarian and Pedagogical Academy, Kremenets, Ukraine.
}

\begin{abstract}
Purpose: The aim of this work to determine the influence of a program containing exercises in a closed kinematic chain, eccentric and strength exercises on injuries of students - rock climbers. Methods: Participants in this study were 84 male amateur climbing students, aged 18-19, 40 athletes were in the intervention group and 44 in the control group. In the intervention group, the program for the injuries prevention has been stalled. The program included exercises that are performed in a closed kinematic chain in combination with exercises that are performed in eccentric mode and strength exercises. We determined the Incidence rate ratio and confidence intervals. The Incidence rate ratio was determined by the by Fisher exact test. Results: The significant influence of the developed program on the reduction of injuries among the athletes of the intervention group was revealed. Injury rate per 1000 AEs recorded of all shoulder injuries in the control group was 3.182, in the intervention group was $0.5, P<0.001$. The incidence rate ratio for mild shoulder injuries was 0.861 $(0.737 ; 1.007)$. The incidence rate ratio for moderate shoulder injuries was $0.862(0.751 ; 0.990 ; P=0.039)$. The incidence rate ratio for severe shoulder injuries was $0.864(0.768 ; 0.971 ; P=0.017)$. Conclusions: The use of exercises in a closed kinematic chain and exercises in an eccentric mode reduces the Incidence rate ratio of shoulders among students - amateur climbers. The incidence rate ratio decreases in the intervention group for mild, moderate, and severe shoulder injuries.
\end{abstract}

Key words: rock climbing, injury, prevention, kinematic chain

\section{Introduction}

Currently, rock climbing is becoming an increasingly popular sport among young people [13], [14], [18]. Therefore, rock climbing is introduced into many higher educational institutions that train specialists in the field of physical culture, as one of the main sports. Rock climbing has now become an Olympic sport [18]. This leads to an increase in the volume and intensity of stress and the number of injuries. Hochholzer et al. [7], Schoffl et al. [25], [26] revealed a tendency towards a significant increase in the injuries of the upper limb girdle in rock climbing. The most commonly

* Corresponding author: Zhanneta Kozina, Department of Olympic and Professional Sport, Sport Games and Tourism, H.S. Skovoroda Kharkiv National Pedagogical University, Alchevskykh str. 29, 61002, Kharkiv, Ukraine. E-mail: zhanneta.kozina@gmail.com

Received: February 18th, 2021

Accepted for publication: April 17th, 2021 
injured areas are fingers, shoulder and forearm [8]-[10], [28].

Backe S., Ericson L., Janson S., Timpka T. in [3] recorded 4.2 injuries per 1000 hours of climbing training, with overload injuries of the upper limbs accounting for $93 \%$ of all injuries. Inflammatory lesions of the tissues of the fingers and wrists were the most common types of injury. Multivariate analysis has shown that being overweight and bouldering increases the risk of primary injury. The risk of re-injury was higher among male climbers and lower among older climbers. The authors concluded that a high percentage of injuries originate from excessive training loads. This indicates that the climbing time and the intensity of the load should be increased gradually and systematically. Climbers should be monitored regularly for signs and symptoms of overexertion. The authors concluded that it necessary to develop the injury prevention program in climbing.

Jones G., Asghar A., Llewellyn D.J. [8] found that about $50 \%$ of climbers suffered more or less 1 injury in the past 12 months, resulting in 275 different anatomical injuries. Twenty-one climbers $(10 \%)$ sustained acute climbing injuries from falls, 67 (33\%) chronic overstrain injuries, and 57 (28\%) acute injuries caused by strenuous climbing movements. Climbers involved in various types of climbing are more susceptible to finger and shoulder injuries. The authors concluded too about the necessarian the injury prevention program in climbing.

Durand-Bechu M., Chaminade B., Belleudy P., Gasq D. [6] described climbing injuries in France between 2004 and 2011. There were 1.49 injuries per 1000 hours of practice. Female climbers accounted for $0.35 \%$ of injuries per year, while the percentage was lower among men $(0.27 \%)$. Climbers between the ages of 19 and 30 suffered the highest injury rate $-0.37 \%$ per year. The most common injuries were fractures and dislocations (39\% and $25 \%$ for men and $30 \%$ and $34 \%$ for women, respectively). The authors concluded that increased prevention is needed to reduce the number of serious accidental injuries.

Jones G. and M.I. Johnson [10] showed that previous trauma is a significant risk factor for re-trauma. Insufficient technical readiness in bouldering and sport climbing was largely associated with repeated injuries. As the number of competitors in competition increases, the likelihood increases that more climbers will sustain an upper limb injury. The authors of papers [19], [23], [25], who studied injuries in rock climbing, came to the conclusion that the upper limbs are most often injured. Shoulder injuries are common injuries in rock climbers. Therefore, the development of programs for the prevention of injuries in rock climbing is necessary.
Climbing injury prevention programs are just beginning to be developed [14]. Therefore, there is not enough literary data at the moment regarding the prevention of injuries in rock climbing. There are indirect assumptions about the positive effect of strength exercises on reducing the level of injuries in rock climbing, but special studies have not been carried out. Aras D., Gül S., Akça F., Gülü M., Güler Özkan, Bıldırcın C., Arslan E., Etinkaya G. [2] investigated the effectiveness of using electrical muscle stimulation in combination with training on a fingerboard. The authors concluded that the use of electrical stimulation in combination with exercises on a fingerboard significantly increases arm muscle strength. Based on the results obtained, the authors conclude that the use of this method can not only increase the strength of the hands, but also prevent injuries. This is because of the fact that muscle strength is one of the factors in the prevention of injury [21], [22], [28].

Currently, there is also some controversy in the use of various means to improve the quality of climbing and the possible prevention of injury. Çetinkaya G. et al. [4] found that modern tools used to improve the grip of fingers to rocks in rock climbing on natural terrain (Chalk) degrade the condition of rocks. The authors recommended talking with climbers and motivating them to use other means. But other remedies are not popular with climbers, and their effectiveness has not yet been proven. Therefore, the development of a special injuries prevention program in rock climbing is of particular importance.

Thus, the literature data indicate a high susceptibility to injuries of the upper limbs in rock climbing. This indicates the need to develop injuries prevention program in rock climbing. However, at the moment, we have not found research on injury prevention programs in rock climbing. At the same time, there is a large amount of research on injury prevention programs in other sports that are popular among students [20], [21], [22].

In works [17], [21], [22] it was shown that the most effective programs for injury prevention are complex programs that include neuromuscular training. The authors noted the need to combine comprehensive programs with various educational programs for informing about the causes of injuries and means of preventing injuries. One of the important components of neuromuscular training injury prevention programs are exercises in a closed kinematic chain and exercises in an eccentric mode [5], [21].

Thus, Coppack et al. [5] showed the effectiveness of an injury prevention program for girls serving in the army, one of the components of which was exer- 
cises in a closed kinematic chain for the quadriceps muscle. The exercises were also aimed at strengthening the gluteal muscles. A $75 \%$ reduction in injury risk was found (unadjusted hazard ratio $=0.25 ; 95 \%$ CI, 0.13-0.52; $P<0.001$ ), and it was concluded that an injury prevention program that includes closedloop exercise chain is effective. Augustsson et al. [24] showed a higher efficiency of exercises in a closed kinematic chain compared to exercises in an open kinematic chain for gaining muscle mass and increasing the jump upward.

Currently, there is also a large number of techniques aimed at improving the coordination abilities of athletes in various sports [1], [11], [16]. Coordination abilities are a necessary component of the technical training of athletes and injury prevention [14], and therefore their development will be effective for these purposes. One of the components of coordination is also the development of strength [2], [21] and the development of conscious self-control over the technique of performing various movements [15]. Thus, among the programs aimed at preventing injuries in various sports, exercises in a closed kinematic chain, exercises performed in eccentric mode and strength exercises are often found. In our opinion, combining these exercises to prevent shoulder injuries in climbing will be effective.

In this regard, a hypothesis that the use of exercises in a closed kinematic chain, exercises in an eccentric mode and strength exercises can be effective for the prevention of shoulder injuries in student climbers was formulated.

The purpose of the work was to determine the influence of a program containing exercises in a closed kinematic chain, eccentric and strength exercises on injuries of students-rock climbers.

\section{Materials and methods}

\subsection{Participants and randomization}

The participants in this study were 84 male students engaged in rock climbing at an amateur level in the cities of Ukraine (Kharkiv, Dnipro, Lyuviv, Vinnitsa, Kamenets-Podolsky, Kiev), aged 18-19. All participants agreed to participate in the study.

All athletes were also students of physical education faculties of Ukrainian universities. All athletes gave written consent to participate in the experiment. The health status of the athletes was monitored during the first 2 weeks of the study using routine medical examinations conducted by a physician. Athletes were also followed for 6 months to assess baseline injury rates.

An independent statistician randomized the athletes into a control group and an intervention group using a random distribution method with a random number generator program. As a result of randomization, 40 athletes were in the intervention group and 44 athletes were in the control group.

The groups were compared in terms of body length, body weight, climbing experience and the number of injuries during the period of 6 months observed before the start of the experiment. For all these indicators, the groups did not differ significantly among themselves.

Table 1. Comparison of injuries of Shoulders of rock-climbers between the Control $(n=44)$ and the Intervention Groups $(n=40)$ within six months before the experiment

\begin{tabular}{|c|c|c|c|c|c|c|c|c|}
\hline \multirow{2}{*}{$\begin{array}{l}\text { Injury } \\
\text { severity }\end{array}$} & \multicolumn{3}{|c|}{ Control Group } & \multicolumn{3}{|c|}{ Intervention Group } & \multirow{2}{*}{$\begin{array}{l}\operatorname{IRR}(95 \% \mathrm{CI})^{\mathrm{a} ; \mathrm{b}} \\
\quad \operatorname{OR}(95 \% \mathrm{CI})^{\mathrm{c}}\end{array}$} & \multirow[b]{2}{*}{$P$-value ${ }^{\mathrm{d}}$} \\
\hline & Injuries, No. & $\begin{array}{l}\text { AEs, } \\
\text { No. }\end{array}$ & $\begin{array}{l}\text { Injury } \\
\text { Rate }^{\mathrm{a}}\end{array}$ & $\begin{array}{c}\text { Injuries, } \\
\text { No. }\end{array}$ & AEs, No. & $\begin{array}{c}\text { Injury } \\
\text { Rate }\end{array}$ & & \\
\hline \multirow{3}{*}{ Easy } & \multirow{3}{*}{4} & \multirow{3}{*}{3300} & \multirow{3}{*}{1.21} & \multirow{3}{*}{5} & \multirow{3}{*}{3000} & \multirow{3}{*}{1.67} & $1.039(0.894 ; 1.207)^{\mathrm{a}}$ & \multirow{3}{*}{$0.439^{d}$} \\
\hline & & & & & & & $0.727(0.21 ; 2.521)^{\mathrm{b}}$ & \\
\hline & & & & & & & $0.7(0.174 ; 2.813)^{\mathrm{c}}$ & \\
\hline \multirow{3}{*}{ Average } & \multirow{3}{*}{3} & \multirow{3}{*}{3300} & \multirow{3}{*}{0.91} & \multirow{3}{*}{2} & \multirow{3}{*}{3000} & \multirow{3}{*}{0.67} & $0.981(0.881 ; 1.092)^{\mathrm{a}}$ & \multirow{3}{*}{$0.546^{\mathrm{d}}$} \\
\hline & & & & & & & $1.364(0.240 ; 7.747)^{\mathrm{b}}$ & \\
\hline & & & & & & & $1.390(0.220 ; 8.778)^{\mathrm{c}}$ & \\
\hline \multirow{3}{*}{ Heavy } & \multirow{3}{*}{1} & \multirow{3}{*}{3300} & \multirow{3}{*}{0.61} & \multirow{3}{*}{1} & \multirow{3}{*}{3000} & \multirow{3}{*}{1.00} & $1.002(0.937 ; 1.072)^{\mathrm{a}}$ & \multirow{3}{*}{$0.729^{d}$} \\
\hline & & & & & & & $0.909(0.059 ; 14.058)^{\mathrm{b}}$ & \\
\hline & & & & & & & $0.907(0.055: 14.997)^{\mathrm{c}}$ & \\
\hline
\end{tabular}

AEs - athlete * exposure (training sessions, competitions), Injury rate indicates the number of injuries per 1000; IRR - incidence rate ratio: ${ }^{a}$ Incidence rate ratio for cohort (injuries $=$ no), ${ }^{b}$ Incidence rate ratio for cohort (injuries $=$ yes), ${ }^{c}$ OR - Odds Ratio for group (control/intervention); CI - confidence interval (Lower bound; Upper bound); ${ }^{\mathrm{d}}$ By Fisher exact test. 
Before the experiment, groups were distinguished not significantly in terms of body length, body weight, climbing experience and the number of injuries $(p>0.05)$. The control group had the following indicators: the height of athletes of $172.5 \pm 8.5 \mathrm{~cm}$, body weight of $65.2 \pm 6.5 \mathrm{~kg}$, climbing experience of $2.4 \pm 1.2$ years. The intervention group had the following indicators: the height of $173.4 \pm 8.7 \mathrm{~cm}$, body weight of $66.1 \pm 6.6 \mathrm{~kg}(p>0.05)$, climbing experience of $2.2 \pm 1.4$ years. The number of shoulder injuries of varying severity recorded during the 6 months prior to the experiment is presented in Table 1. The incidence rate ratio for cohort for minor shoulder injuries was 1.039 (95\% CI, 0.894; 1.207) (Table 1$)$. The incidence rate ratio for cohort for moderate shoulder injuries was 0.981 (95\% CI, 0.881; 1.092) (Table 1). The incidence rate ratio for cohort for severe shoulder injuries was 1,002 (95\% CI, 0.937; 1.072) (Table 1). The incidence rate ratio for all studied injuries is not reliable $(p=0.385-0.729)$ (Table 1$)$.

\subsection{Experimental protocol}

Initially, shoulder injuries were recorded in both groups for 6 months to determine the initial level of injury. Then, an experiment was started, which lasted for 1 year. The groups trained according to the generally accepted plan 3-4 times a week, the number of training sessions was the same in both groups during the year and was 150 . In the experimental group the developed program of injury prevention was applied.

The basic program, according to which the control and experimental groups were trained, was the same for both groups. In the intervention group (experimental), athletes performed additionally the exercises we proposed. The exercises were performed on each training session (3-4 times a week). The intervention program was allocated 15 minutes for each training session. Athletes and coaches recorded in their diaries the fact of the application of the intervention program.

\subsection{Injury registration method}

Cases of injuries and diseases of the upper extremities were recorded first for 6 months to determine the initial level of injury in both groups, and then - for a year in both groups. The following injuries were registered: shoulder injuries in severity: minor, moderate, severe. Minor injuries included those that healed in less than 1 month, medium injuries to those that healed in $2-3$ months, and complex injuries to those that healed within 6-12 months. Injuries were recorded independently by athletes, coaches and teachers. The severity of injuries was determined by the time required for complete recovery.

\subsection{Intervention program}

The basic program, according to which the control and experimental groups were trained, was the same for both groups. In the intervention group (experimental), athletes performed additionally the exercises we proposed. The exercises were performed on each training session (3-4 times a week). The intervention program was allocated 15 minutes for each training session. Athletes and coaches recorded in their diaries the fact of the application of the intervention program.

Based on our biomechanical analysis of climbing techniques in previous studies [13], [14], exercises were selected and systematized to prevent injuries of the upper extremities. Biomechanical analysis [13], [14] allowed to determine that for injury prevention it is necessary to form the correct technique of performing the basic elements in climbing and to determine the tasks for the use of means for injury prevention in climbing: 1 - strengthening the muscles involved in performing proper movement; 2 - formation of functional movement to develop exercises for coordinated work of the muscles of the torso, upper and lower extremities.

As shown by our previous studies [13], [14], the correct technique of hang on one arm in climbing involves the inclusion of muscles not only of the upper extremities, but also the muscles of the torso and legs (Fig. 1b). In the case of incorrect hang on one arm technique, mainly the muscles of the upper limb are involved (Fig. 1a). Therefore, with the right technique of the hang on one arm, the inclusion of the muscles of the torso and legs creates additional links in the kinematic chain. As a result, the upper limb has less load than with the wrong technique of hanging. This ensures the achievement of sports results and prevents injuries. Our injury prevention program involved a conscious focus on proper climbing techniques.

Based on our findings and on the results of research [5], [24], we included exercises performed in a closed kinematic chain in the program of injury prevention (Fig. 2) because a closed kinematic chain involves all the muscles that make up this kinematic chain. We used exercises in closed kinematic chain, with an emphasis on shoulder retraction to improve muscle coordination. 
(a)

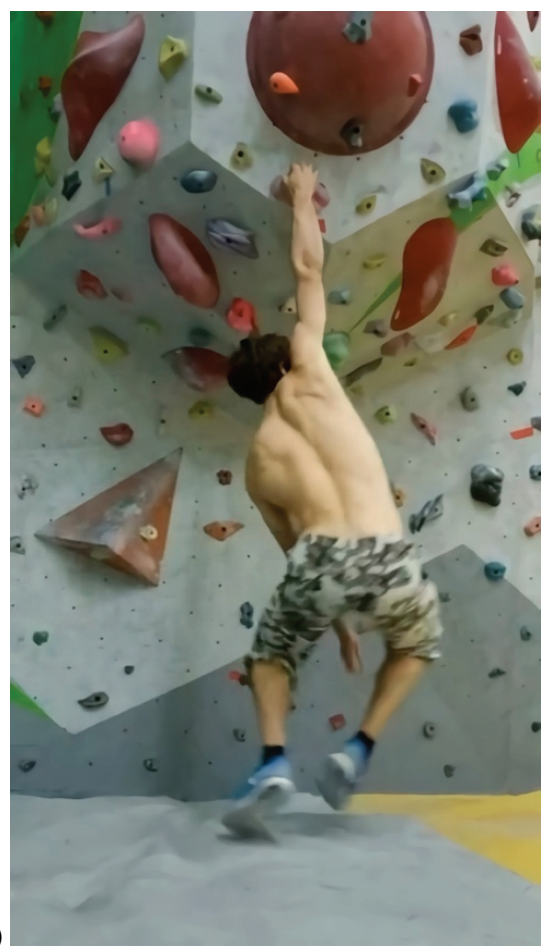

(b)

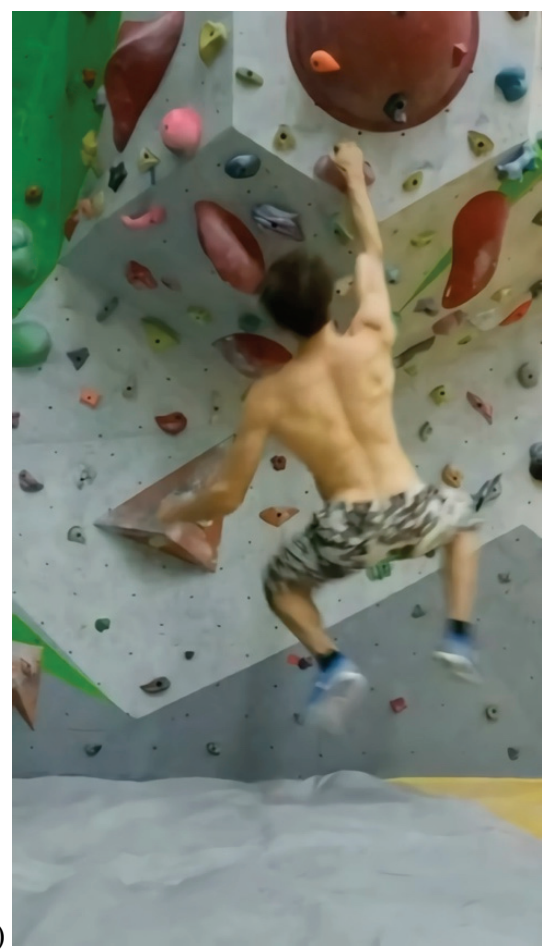

Fig. 1. (a) The incorrect technique of hanging on one arm in climbing (source: photo by author - Serhii Kozin] [13], [14]. The photo shows Serhii Kozin, who gave written consent to the use of his photo in this article. A stamped document is attached. (b) Correct technique of hanging on one arm in climbing (source: photo by the author - Serhii Kozin] [13], [14]. The photo shows Serhii Kozin, who gave written consent to the use of his photo in this article. A stamped document is attached (a)

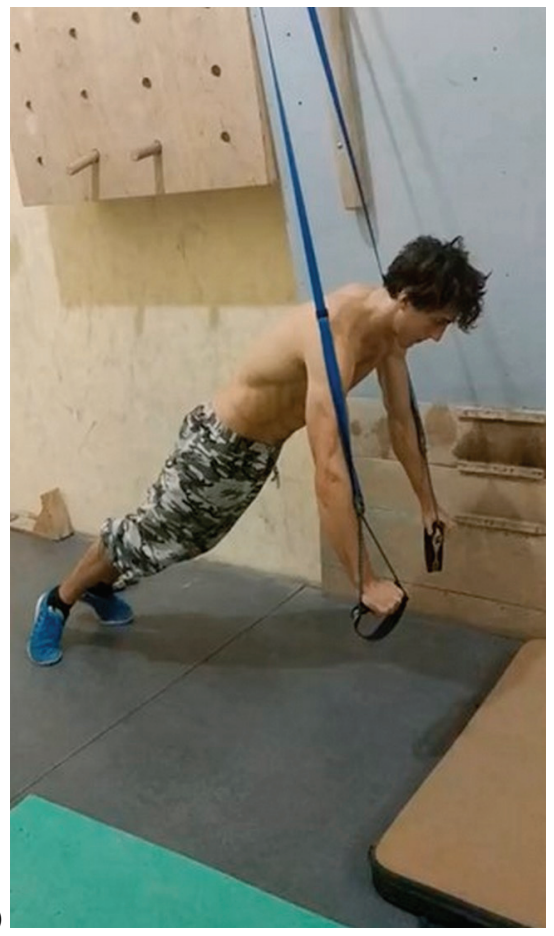

(b)

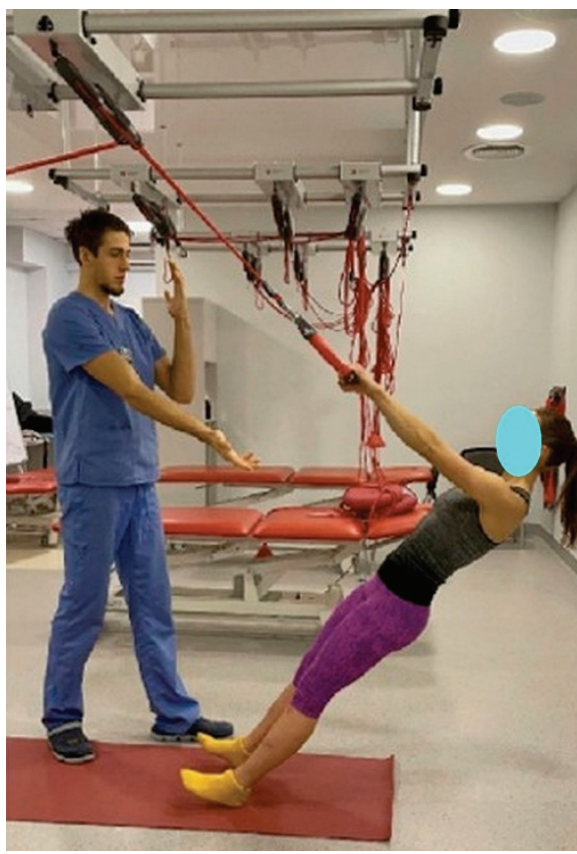

(c)

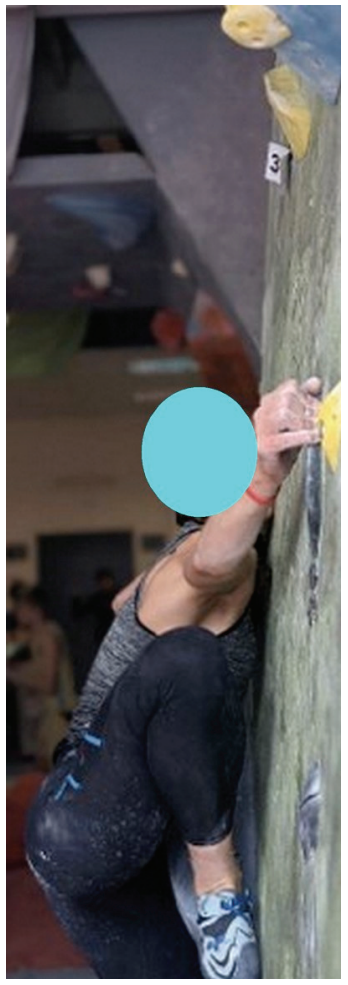

Fig. 2. Example of an exercise in a closed kinematic chain: (a) push-ups on the rings; (b) Leg-supported pull-ups;

(c) illustration of a closed kinematic chain in climbing. (source: photos by the author - Serhii Kozin). The photos show Serhii Kozin, who gave written consent to the use of his photo in this article 
Examples of exercises in closed kinematic chain:

1. Push ups on the rings (Fig. 2a). Starting position: support with two straight hands on gymnastic rings, feet rest on toes, back is straight. Flexion and extension of the arms in focus on the rings; keep the back straight, do not take feet off the floor. Number of repetitions - 10-20 times depending on the level of preparedness of students.

2. Pulling up in an emphasis (Fig. 2b). Starting position: hold the crossbar with hands straight with feet on the floor. The back is straight. Flexion and extension of the arms. Keep the back straight, do not take feet off the floor. Number of repetitions -10-20 times depending on the level of preparedness of students.

3. Illustration of a closed kinematic chain in rock climbing. Climbing on a climbing stand with support on 3 points ( 2 arms and 1 leg or 2 legs and $1 \mathrm{arm})$ (Fig. 2c). When climbing, athletes must consciously control the involvement of muscles not only in the arms, but also in the torso and legs.

Exercises in closed kinematic chain act on the entire kinematic circuit completely, more evenly distribute the load on all links of the chain. The program also involved a conscious concentration on the inclusion of all the muscles of the closed kinematic chain in the process of performing each movement. Autogenic training was used to improve the ability to concentrate [15].

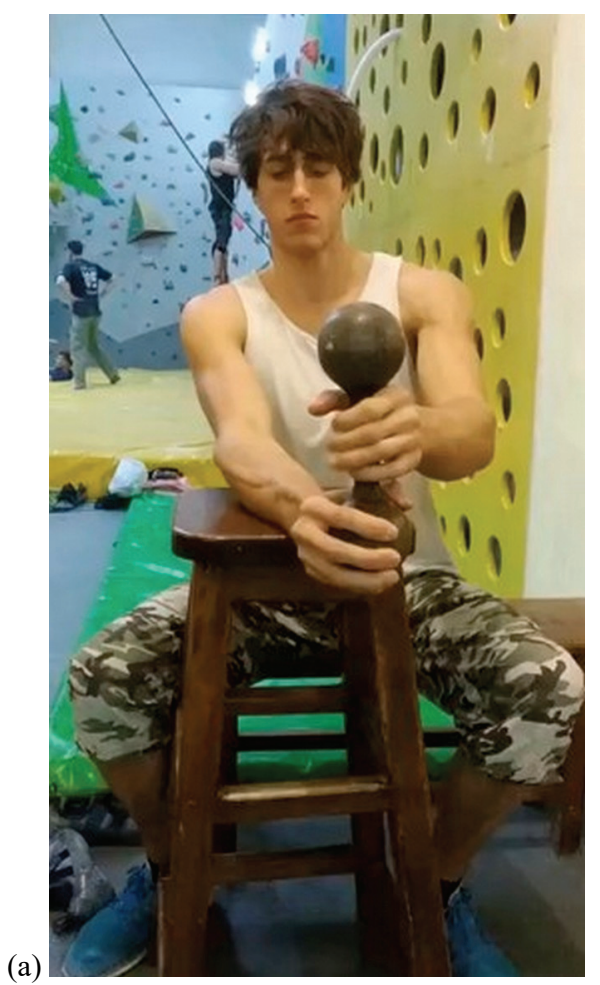

Also, exercises that are performed in an eccentric mode were included in the training process (Fig. 3).

Example of an exercise in eccentric mode (Fig. 3): Starting position: sitting on a chair, back is straight, one arm resting on a support; hold a dumbbell weighing $4 \mathrm{~kg}$ vertically in this hand (Fig. 3a). Slowly perform pronation of the hand (eccentric mode) (Fig. 3b). Return to starting position, supporting the dumbbell with the other hand. Number of repetitions - 5-10 times depending on the level of preparedness of students.

The program involved conscious concentration on the slow execution of pronation-supination and on the smoothest inclusion of muscles in the eccentric mode.

We used exercises to strengthen the muscles that provide proper climbing techniques.

Example of strength exercise:

Pull-ups on the crossbar (Fig. 4): keep the back straight, when pulling the chin should reach above the crossbar; Number of repetitions - 5-20 depending on the level of preparedness of students.

We held a seminar "Therapeutic biomechanics in climbing" for athletes, coaches and rock climbing teachers at universities 2 weeks before the experiment. Athletes, coaches and university climbing instructors who agreed to participate in the study in the intervention group were participants in the workshop. At the seminar, we gave theoretical information on the causes

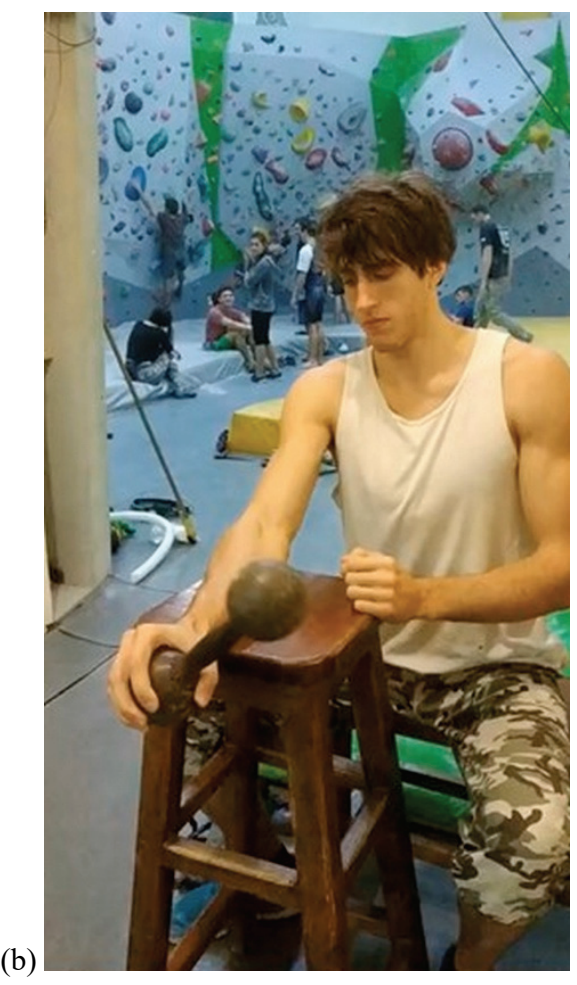

Fig 3. Exercises in eccentric mode: Initial position (a) and final position (b). (source: photos by the author - Serhii Kozin). The photos show Serhii Kozin, who gave written consent to the use of his photo in this article 
of injuries in rock climbing, as well as information on the correct technique of hang on one hand in rock climbing. We also trained participants in the intervention program in closed-chain exercises and exercises that are performed in eccentric mode.

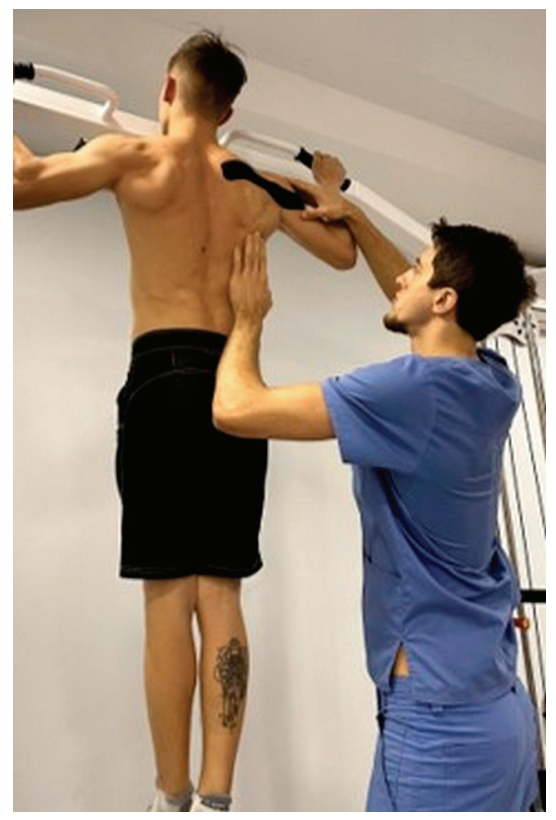

Fig. 4. An example of an exercise to strengthen the muscles that ensure the climbing technique (source: photo by the author-Serhii Kozin)

\subsection{Statistical analysis}

We presented the injury rate as the number of injuries per $1000 \mathrm{AEs}$, and we defined $\mathrm{AE}$ as the number of athletes in a group multiplied by the number of all training sessions and competitions in which they participated $(\mathrm{AE}=$ athlete $*$ exposure (training sessions, competitions)) [12], [27]. The number of trainings and competitions was the same in the control and experimental groups ( 75 before the experiment and 150 during the experiment). The number of students - climbers was 40 for the experimental group and 44 for the control).

We also determined the following indicators: IRR - incidence rate ratio for cohort (injuries $=$ no), Incidence rate ratio for cohort (injuries $=$ yes); $\mathrm{OR}$ - odds ratio for group (control/intervention); CI - confidence interval (lower bound; upper bound). We used Fisher's exact test to compare injury rates between intervention and control groups. We considered $P<0.05$ to be statistically significant. The reliability of the incidence rate ratio and odds ratio was determined by the by Fisher's exact test too. We determined the significance of the differences in terms of body length, body weight and experience in rock climbing before the start of the experiment using the Student's $t$ and Mann-Withey $U$-test methods. We used SPSS 17.0 for Windows software (SPSS Inc., Chicago, IL, USA), option Crosstabs, Risk) for statistical analysis.

\section{Results}

We found that the baseline rate of all shoulder injuries recorded within 6 months prior to the experiment was 9 injuries in the control group and 10 in the experimental group. The number of AEs in the 6 months before the start of the experiment was 3300 in the control and 3000 in the intervention group. Injury rate per 1000 AEs in the control group was 2.727 (95\% CI, $0.89 ; 4.564)$, it was in the intervention group 3.333 (95\% CI, 1.567; 5.099), $P>0.05$ (Table 1).

The total number of all recorded shoulder injuries during 1 year of the experiment was 21 in the control group and 3 in the experimental group. The number of AEs during 1 year of the experiment was 6600 in the control group and 6000 in the intervention group. Injury rate per $1000 \mathrm{AEs}$ of all recorded shoulder injuries in the control group during 1 year of the experiment was 3.182 (95\% CI, 1.061; 5.367), it was in the intervention group $0.5(95 \% \mathrm{CI}, 0.068 ; 1.375)$, $P<0.001$.

Injury rate of mild shoulder injuries per $1000 \mathrm{AEs}$ during 1 year of the experiment in the control group was $3.182(95 \% \mathrm{CI}, 1.061 ; 5.303)$, it was in the intervention group 0.5 (95\% CI, 0.068; 0.968). Incidence rate ratio for cohort (injuries $=$ no) for mild shoulder injuries was $0.861(0.737 ; 1.007)$ (Table 2). We also found that the injury rate of moderate shoulder injuries per 1000 AEs during 1 year of the experiment in the control group was $1.06(95 \% \mathrm{CI}, 0.347 ; 1.773)$, it was in the intervention group 0.17 (95\% CI, 0.098; 1.172). The incidence rate ratio for cohort (injuries $=$ no) for moderate shoulder injuries was $0.862(0.751$; $0.990 ; P=0.039$ ) (Table 2). Our study also showed that the injury rate of severe shoulder injuries per 1000 AEs during 1 year of the experiment in the control group was $0.91(95 \% \mathrm{CI}, 0.124 ; 1.695)$, it was in the intervention group 0 (there were no severe injuries in the experimental group). revealed). The incidence rate ratio for cohort (injuries $=$ no) for severe shoulder injuries was $0.864(0.768 ; 0.971 ; P=0.017)$ (Table 2). The incidence rate ratio for cohort (injuries $=$ yes) shows that the use of the developed program reduces the risk of mild shoulder injuries by 3.636 times, and the risk of moderate shoulder injuries by 6.364 times. This value for severe shoulder injuries was not deter- 
Table 2. Comparison of injuries of Shoulders of rock-climbers between the control $(n=44)$ and the intervention groups $(n=40)$ during the year of the experiment

\begin{tabular}{|c|c|c|c|c|c|c|c|c|}
\hline \multirow{2}{*}{$\begin{array}{l}\text { Injury } \\
\text { severity }\end{array}$} & \multicolumn{3}{|c|}{ Control Group } & \multicolumn{3}{|c|}{ Intervention Group } & \multirow{2}{*}{$\begin{array}{c}\operatorname{IRR}(95 \% \mathrm{CI})^{\mathrm{a} ; \mathrm{b}} ; \\
\operatorname{OR}(95 \% \mathrm{CI})^{\mathrm{c}}\end{array}$} & \multirow{2}{*}{$P$-value ${ }^{\mathrm{b}}$} \\
\hline & Injuries, No. & AEs, No. & Injury Rate & Injuries, No. & AEs, No. & Injury Rate & & \\
\hline \multirow{3}{*}{ Easy } & \multirow{3}{*}{8} & \multirow{3}{*}{6600} & \multirow{3}{*}{1.20} & \multirow{3}{*}{2} & \multirow{3}{*}{6000} & \multirow{3}{*}{0.33} & $0.861(0.737 ; 1.007)^{\mathrm{a}}$ & \multirow{3}{*}{$0.061^{\mathrm{d}}$} \\
\hline & & & & & & & $3.636(0.820 ; 16.121)^{b}$ & \\
\hline & & & & & & & $4.222(0.840 ; 21.232)^{\mathrm{c}}$ & \\
\hline \multirow{3}{*}{ Average } & \multirow{3}{*}{7} & \multirow{3}{*}{6600} & \multirow{3}{*}{1.06} & \multirow{3}{*}{1} & \multirow{3}{*}{6000} & \multirow{3}{*}{0.17} & $0.862(0.751 ; 0.990)^{\mathrm{a}}$ & \multirow{3}{*}{$0.039^{\mathrm{d}}$} \\
\hline & & & & & & & $6.364(1.818 ; 19.485)^{\mathrm{b}}$ & \\
\hline & & & & & & & $7.378(2.865 ; 12.902)^{\mathrm{c}}$ & \\
\hline \multirow{3}{*}{ Heavy } & \multirow{3}{*}{6} & \multirow{3}{*}{6600} & \multirow{3}{*}{0.91} & \multirow{3}{*}{0} & \multirow{3}{*}{6000} & \multirow{3}{*}{0.00} & $0.864(0.768 ; 0.971)^{\mathrm{a}}$ & \multirow{3}{*}{$0.017^{\mathrm{d}}$} \\
\hline & & & & & & & - & \\
\hline & & & & & & & - & \\
\hline
\end{tabular}

AEs - athlete * exposure (training sessions, competitions); Injury rate indicates the number of injuries per $1000 \mathrm{AEs}$; IRR - incidence rate ratio: ${ }^{a}$ Incidence rate ratio for cohort (injuries $=$ no), ${ }^{\mathrm{b}}$ Incidence rate ratio for cohort (injuries $=$ yes), ${ }^{\mathrm{c}} \mathrm{OR}-$ odds ratio for group (control/intervention); CI - confidence interval (Lower bound; Upper bound); ${ }^{\mathrm{d}}$ By Fisher exact test.

mined, since no severe shoulder injuries were recorded in the intervention group (Table 2). We also found a significant decrease in odds ratio for group (control/intervention) under the influence of our injury prevention program (Table 2).

Thus, our study showed that the use of exercises in a closed kinematic chain and exercises in an eccentric mode with strength exercises reduces the incidence rate ratio of the shoulders in students - amateur climbers. The incidence rate ratio decreases for mild, moderate, and severe shoulder injuries, but a significant decrease was found for moderate and severe injuries. Severe shoulder injuries were not detected in the experimental group during the course of the experiment.

\section{Discussion}

To our knowledge, this is one of the first randomized trials to prevent shoulder injury in rock climbing. The hypothesis about the effectiveness of the use of exercises in a closed kinematic chain with eccentric and strength exercises for the prevention of injuries in rock climbing was confirmed. We obtained a significant reduction in injury rate in terms of incidence rate ratio and Odds Ratio for moderate shoulder injuries and in terms of incidence rate ratio for severe injuries. It should be noted that no severe shoulder injuries were found in the intervention group.

The statement about the effectiveness of the use of exercises in a closed kinematic chain for the prevention of injuries was based on the literature data [5], [17], [24] and on the results of our previous studies [13], [14]. A closed kinematic chain involves the in- clusion of all the muscles that form this kinematic chain. Copack et al. [5] also recommend to prevent injuries to perform exercises in a closed kinetic chain for the quadriceps muscle and gluteal eccentric, as well as static stretching of the quadriceps muscle, hamstring, gastrocnemius muscle and iliotibial ligament. The odds ratio of injury without application and with the use of this program is $0.26(0.13-0.53)$.

Our program is based on the position formulated in our previous works [13]. For qualified climbers, the total force to provide the suspension position is significantly greater than that of non-qualified climbers. This is due to the fact that in qualified athletes not only the muscles of the upper limb (as in unskilled athletes), but also the muscles of the trunk and legs, are involved in supporting the suspension position on one arm during climbing, creating another link in the kinematic chain. Accordingly, the upper limb has a lower load compared to the technique of unskilled athletes. This provided a theoretical basis for the formation of the most effective climbing technique, ensuring the achievement of a sports result and preventing injury. Effective climbing technique activate not only the muscles of the arms, but also the muscles of the legs and trunk, therefore it is advisable to use exercises in a closed kinematic chain.

Exercising in a closed kinematic chain contributes to the inclusion of all the muscles that form this kinematic chain. This forms the skill of using not only the muscles of the arms, but also the muscles of the trunk and legs when performing hang on one hand in rock climbing [13]. Exercises performed in eccentric mode promote smooth activation of the antagonist muscles. This contributes to their strengthening during movements aimed at maintaining the position of the body when performing interceptions while climbing. There- 
fore, we can conclude that the combination of these exercises with each other and with strength exercises has a theoretical basis, and in our study it was experimentally confirmed.

Another feature of our climbing injury prevention program is that the program includes exercises specific to climbing. In the analyzed literature on injury prevention in various sports, all proposed programs included general exercises to strengthen the muscles of the core, develop balance, and strengthen the muscles of the legs. In our study, injury prevention exercises specific to rock climbing were used. It should be noted that the evidence for the effectiveness of climbing-specific exercises, including closed-chain exercises with eccentric and strength exercises, is relatively new.

\section{Conclusions}

The total number of all recorded shoulder injuries during 1 year of the experiment was 21 in the control group and 3 in the experimental group. Injury rate per 1000 AEs of all recorded shoulder injuries in the control group during 1 year of the experiment was 3.182 $(95 \% \mathrm{CI}, 1.061 ; 5.367)$, it was in the intervention group 0.5 (95\% CI, 0.068; 1.375), $P<0.001$.

Injury rate of mild shoulder injuries per $1000 \mathrm{AEs}$ during 1 year of the experiment in the control group was $3.182(95 \% \mathrm{CI}, 1.061 ; 5.303)$, it was in the intervention group 0.5 (95\% CI, 0.068; 0.968). Injury rate of moderate shoulder injuries per 1000 AEs during 1 year of the experiment in the control group was 1.06 (95\% CI, 0.347; 1.773), it was in the intervention group 0.17 (95\% CI, 0.098; 1.172). Injury rate of severe shoulder injuries per 1000 AEs during 1 year of the experiment in control in the first group it was 0.91 (95\% CI, 0.124; 1.695), it was in the intervention group 0 (no severe injuries were detected in the experimental group).

Incidence rate ratio for cohort (injuries $=$ no) for mild shoulder injuries during 1 year of the experiment was $0.861(0.737 ; 1.007)$. The incidence rate ratio for cohort (injuries $=$ no) for moderate shoulder injuries during 1 year of the experiment was $0.862(0.751 ; 0.990$; $P=0.039$ ). Incidence rate ratio for cohort (injuries $=$ no) for severe shoulder injuries during 1 year of the experiment was $0.864(0.768 ; 0.971 ; P=0.017)$.

The use of exercises in a closed kinematic chain with exercises in an eccentric mode and strength exercises reduces the incidence rate ratio of shoulders among students - amateur climbers. The incidence rate ratio decreases for mild, moderate, and severe shoul- der injuries, but a significant decrease was found for moderate and severe injuries. Application of the developed program reduces the risk of mild shoulder injuries by 3.636 times, and the risk of moderate shoulder injuries - by 6.364 times. This value for severe shoulder injuries was not determined as no severe shoulder injuries were recorded in the intervention group.

\section{Acknowledgements}

We express our sincere gratitude to all participants for following all our recommendations regarding the training process during the study, as well as for the test participation.

The study was conducted in accordance with the research work of Ministry of Education and Science of Ukraine for 2019-2020 "Theoretical and methodological foundations of technology development for the restoration of musculoskeletal system and functional state and prevention of injuries of representatives of different age groups in physical culture and sports" (No. 0119U100634).

\section{References}

[1] Al-Ravashdeh A.B., Kozina Z.L., BazilyUK T.A., ILNICKAYA A.S., Influence of skills' training methodic with the application of interdisciplinary connections on motor fitness of senior pupils in light athletic, Pedagog. Psychol. Med.-biol. Probl. Phys. Train. Sports, 2015, 19 (9), 3-11, DOI: 10.15561/ 18189172.2015.0901.

[2] Aras D., GÜl S., AKÇA F., GÜLÜ M., ÖZKAN G., BILdirCIN C., ARSlan E., ÇetinKaya G., Four-week of local electromyostimulaiton training on fingerboard increases the isokinetic wrist strength and endurance, Phys. Educ. Stud., 2020, 24 (3), 127-34, DOI: 10.15561/20755279.2020.0301.

[3] BACKe S., ERICSON L., JANSON S., TIMPKA T., Rock climbing injury rates and associated risk factors in a general climbing population, Scand. J. Med. Sci. Sports, 2009, 19 (6), 850-856, DOI: $10.1111 / \mathrm{j} .1600-0838.2008 .00851 . x$.

[4] ÇETINKAYA G., GÜNGÖR A., ARAS D., Impact of the "Chalk" on perceived visual quality and the willingness to climb: a research on sports climbing, Pedagogy Phys. Cult. Sports, 2021, 25 (1), 15-3, DOI: 10.15561/26649837.2021.0103.

[5] COPpack R.J., Etherington J., Wills A.K., The effects of exercise for the prevention of overuse anterior knee pain, Am. J. Sports Med., 2011, 39 (5), 940-948, DOI: 10.1177/ 0363546510393269.

[6] Durand-Bechu M., Chaminade B., Belleudy P., Gasq D., Rock-climbing injuries in France from 2004 until 2011, Sci. Sport, 2014, 29 (3), 125-130, DOI: 10.1016/j.scispo.2013.12.005.

[7] HochHolzer T., SCHOFFL V.R., Epiphyseal fractures of the finger middle joints in young sport climbers, Wilderness Environ. Med., 2005, 16 (3), 139-142, DOI: 10.1580/pr15-04.1.

[8] Jones G., Asghar A., Llewellyn D.J., The epidemiology of rock-climbing injuries, Br. J. Sports Med., 2008, 42 (9), 773-778, DOI: $10.1136 /$ bjsm.2007.037978.

[9] Jones G., Johnson M.I., A Critical Review of the Incidence and Risk Factors for Finger Injuries in Rock Climbing, Curr. Sports Med. Rep., 2016, 15 (6), 400-409, DOI: 10.1249/ JSR.0000000000000304. 
[10] Jones G., Llewellyn D., Johnson M.I., Previous injury as a risk factor for reinjury in rock climbing: A secondary analysis of data from a retrospective cross-sectional cohort survey of active rock climbers, BMJ Open SEM, 2015, 1 (1), 1-5, DOI: 10.1136/bmjsem-2015-000031.

[11] KARTAL A., The relationships between dynamic balance and sprint, flexibility, strength, jump in junior soccer players, Pedagogy Phys. Cult. Sports, 2020, 24 (6), 285-289, DOI: 10.15561/ 26649837.2020.0602.

[12] Knowles S., Marshall S.W., Guskiewicz K.M., Estimating rates and risks in sports injury research, J. Athl. Train., 2006, 41 (2), 207-215.

[13] Kozin S.V., Safronov D.V., Kozina Z.L., Kniaz H.O., ProskuRnia O., Prontenko K., Lahno O., Goncharenko V., KhOlODNIY A., Comparative biomechanical characteristics of one-arm hang in climbing for beginners and qualified athletes, Acta Bioeng. Biomech., 2020, 22 (1), 57-67, DOI: 10.37190/ABB-01440-2019-03.

[14] KozIn S.V., Biomechanical substantiation of the technique of hanging in rock climbing, Health, Sport, Rehabilitation, 2019, 5 (1), 25-35, DOI: 10.34142/HSR.2019.05.01.03.

[15] Kozina Z.L., IERMakov S.S., Bartík P., Yermakova T.S., Michal J., Influence of self-regulation psychological and physical means on aged people's functional state, J. Hum. Sport., 2018, 13 (1), 99-115, DOI: 10.1016/j.jshs. 2016.07.002.

[16] Kozina Z.L, GoloborodKo Y.A, BoichuK Y.D., SobKo I.M., REPKO O.O., BAZILYUK T.A. et.al., The influence of a special technique for developing coordination abilities on the level of technical preparedness and development of psycho-physiological functions of young volleyball players 14-16 years of age, J. Phys. Educ. Sport, 2018, 18 (3), 1445-1454, DOI: 10.7752/ jpes.2018.03214.

[17] LaBella C.R., Huxford M.R., Grissom J. et al., Effect of neuromuscular warm-up on injuries in female soccer and basketball athletes in urban public high schools, Arch. Pediatr. Adolesc. Med., 2011, 165 (11), 1033-1040, DOI: 10.1001/ archpediatrics.2011.168.

[18] LutTer C., El-SheikH Y., Schoff I., SchOFfl V., Sport climbing: medical considerations for this new Olympic discipline,
Br. J. Sports Med., 2017, 51 (1), 2-U5, DOI: 10.1136/bjsports2016-096871.

[19] Merritt A.L., Huang J.I., Hand Injuries in Rock Climbing, J. Hand Surg. (Am. Vol.), 2011, 36A (11), 1859-1861, DOI: 10.1016/j.jhsa.2011.08.020.

[20] Muszkieta R., Napierala M., CieŚlicka M., Zukow W., KozIna Z.L., IERMAKov S.S., GóRnY M., The professional attitudes of teachers of physical education, J. Phys. Educ. Sport, 2019, 19 (Supplement issue 1), 92-99, DOI: 10.7752/jpes.2019.s1014.

[21] PARKKaRi J., TAANILA H., Suni J. et al., Neuromuscular training with injury prevention counseling to decrease the risk of acute musculoskeletal injury in young men during military service: a population-based, randomized study, BMC Med., 2011, 9 (1), 35, DOI: 10.1186/1741-7015-9-35.

[22] Pasanen K., ParkKari J., Pasanen M. et al., Neuromuscular training and the risk of leg injuries in female floorball players: cluster randomised controlled study, Br. J. Sports Med., 2008, 42, 802-805, DOI: 10.1136/BMJ.A295.

[23] Pozzi A., Pivato G., Pegoli L., Hand Injury in Rock Climbing: Literature Review, J. Hand Surg. Asian Pac. Vol, 2016, 21 (1), 13-7, DOI: $10.1142 / \mathrm{S} 2424835516400038$.

[24] Rahlf Augustsson J., Esko A., ThomeE R., Svantesson U., Weight training of the thigh muscles using closed vs. open kinetic chain exercises: A comparison of performance enhancement, J. Orthop. Sports Phys. Ther., 1998, 27 (1), 3-8, DOI: 10.2519/jospt.1998.27.1.3.

[25] Schoeffl V., Hand injuries in rock climbing, Dtsch. Z. Sportmed., 2008, 59 (4), 85-90.

[26] Schoffl V., PopP D., KuPPer T., Schoffl I., Injury Trends in Rock Climbers: Evaluation of a Case Series of 911 Injuries Between 2009 and 2012, Wilderness Environ. Med., 2015, 26 (1), 62-67, DOI:10.1016/j.wem.2014.08.013.

[27] Schulz K.F., GRIMES D.A., Allocation concealment in randomised trials: defending against deciphering, Lancet, 2002, 359 (9306), 614-618, DOI: 10.1016/S0140-6736(02)07750-4.

[28] Woollings K.Y., McKay C.D., Kang J., Meeuwisse W.H., EMERY C.A., Incidence, mechanism and risk factors for injury in youth rock climbers, Br. J. Sports Med., 2015, 49 (1), 44-50, DOI: 10.1136/bjsports. 